Review

\title{
Amino Acid Signaling for TOR in Eukaryotes: Sensors, Transducers, and a Sustainable Agricultural fuTORe
}

\author{
Nanticha Lutt ${ }^{1,2,3}$ and Jacob O. Brunkard $1,2,3, *$ (D) \\ 1 Laboratory of Genetics, University of Wisconsin, Madison, WI 53706, USA; nantichalutt@berkeley.edu \\ 2 Department of Plant and Microbial Biology, University of California, Berkeley, CA 94720, USA \\ 3 Plant Gene Expression Center, USDA Agricultural Research Service, Albany, CA 94720, USA \\ * Correspondence: brunkard@wisc.edu
}

Citation: Lutt, N.; Brunkard, J.O. Amino Acid Signaling for TOR in Eukaryotes: Sensors, Transducers, and a Sustainable Agricultural fuTORe. Biomolecules 2022, 12, 387. https://doi.org/10.3390/ biom12030387

Academic Editors: Kazuhiro Shiozaki and Ted Powers

Received: 26 January 2022 Accepted: 28 February 2022 Published: 2 March 2022

Publisher's Note: MDPI stays neutral with regard to jurisdictional claims in published maps and institutional affiliations.

Copyright: (C) 2022 by the authors. Licensee MDPI, Basel, Switzerland. This article is an open access article distributed under the terms and conditions of the Creative Commons Attribution (CC BY) license (https:// creativecommons.org/licenses/by/ $4.0 /)$.

\begin{abstract}
Eukaryotic cells monitor and regulate metabolism through the atypical protein kinase target of rapamycin (TOR) regulatory hub. TOR is activated by amino acids in animals and fungi through molecular signaling pathways that have been extensively defined in the past ten years. Very recently, several studies revealed that TOR is also acutely responsive to amino acid metabolism in plants, but the mechanisms of amino acid sensing are not yet established. In this review, we summarize these discoveries, emphasizing the diversity of amino acid sensors in human cells and highlighting pathways that are indirectly sensitive to amino acids, i.e., how TOR monitors changes in amino acid availability without a bona fide amino acid sensor. We then discuss the relevance of these model discoveries to plant biology. As plants can synthesize all proteinogenic amino acids from inorganic precursors, we focus on the possibility that TOR senses both organic metabolites and inorganic nutrients. We conclude that an evolutionary perspective on nutrient sensing by TOR benefits both agricultural and biomedical science, contributing to ongoing efforts to generate crops for a sustainable agricultural future.
\end{abstract}

Keywords: amino acid signaling; target of rapamycin; metabolism; mTOR; Sestrin2; GCN2; Castor1; GATOR; Ragulator; Arabidopsis thaliana

\section{Introduction}

Target of rapamycin (TOR) is a serine/threonine kinase that senses environmental cues, especially nutrient availability, to coordinate eukaryotic cellular metabolism [1-5]. TOR supports growth by activating anabolic processes, such as mRNA translation [6-9], nucleotide biosynthesis [10-13], and lipid biosynthesis [14-16], while inhibiting catabolic processes, such as autophagy [17-21]. TOR is especially responsive to amino acid signals. Free amino acids stimulate TOR, which then increases the global rate of protein synthesis to metabolize those amino acids [7,22,23], thereby maintaining metabolic homeostasis while promoting growth and development. The stimulatory effect of amino acids on TOR has primarily been studied in heterotrophs, especially yeast, invertebrates, and mammals, that rely on dietary sources for the 20 proteinogenic amino acids. Unlike these model species, plants are autotrophs that can synthesize all proteinogenic amino acids from inorganic precursors [24-26]. TOR is also responsive to amino acid signals in autotrophic plants [27-30], but the precise amino acids sensed by TOR and the molecular mechanisms of amino acid sensing in plants remain unknown.

In this review, we summarize the current understanding of the molecular pathways of amino acid sensing by TOR in mammalian, invertebrate, and yeast models, discuss the recent literature on amino acid sensing by TOR in plants, address the possibility that TOR responds to both inorganic and organic nitrogenous compounds in plant cells, and propose that a deeper understanding of nitrogen-TOR signaling is urgently needed to minimize reliance on chemical fertilizers for a sustainable agricultural future. We 
argue that a comparative, evolutionary perspective on nutrient sensing by TOR benefits both agricultural and biomedical science, and we highlight how ongoing studies of TOR signaling in plants and algae contribute to these fields.

\section{Sensors and Transducers in Metabolic Signaling}

Multiple amino acid sensors are proposed to regulate TOR activity in humans [23,31]. The relative significance of these sensors and their precise mechanisms of signal transduction are under debate. Therefore, we now define several terms in the field of metabolic signal transduction that are useful for understanding the amino acid-TOR network. A "sensor" protein responds directly to an environmental cue, e.g., by binding to a metabolite that alters the protein's activity or by undergoing a structural change triggered by light or temperature. A classical example of a sensor from plant biology is phytochrome, which reversibly changes conformations in response to red or far-red light [32]. Sensors then engage "transducer" proteins, either indirectly or through direct protein-protein interactions, which may either act on additional transducers to create a chain of signaling events in a pathway or activate the response to a cue. Antibodies, ligand-binding proteins, and hormone receptors are examples of sensors [33]; mitogen-activated protein (MAP) kinases, G-proteins, and TOR itself are examples of transducers.

The distinction between "sensor" and "transducer" is crucial for understanding nitrogen- and amino acid responsive signaling networks in eukaryotic cells. Debates over the function of GCN2 (general control nonderepressible 2), for example, revolve around whether GCN2 is a sensor or a transducer. GCN2 is a serine/threonine kinase that is activated when cells experience extreme stress [34]. Among other substrates, GCN2 phosphorylates the eukaryotic translation initiation factor, eIF $2 \alpha$ (at serine 51 in human eIF2 $\alpha$, which is orthologous to serine 56 in Arabidopsis eIF2 $\alpha$ ), which globally represses translation of most mRNAs and selectively upregulates translation reinitiation of transcripts that encode small, upstream open reading frames (uORFs) in addition to the primary ORF [35-38]. Transcripts with uORFs encode various stress-inducible and starvationresponsive transcription factors [39]. Thus, when GCN2 is active, gene expression is regulated translationally and transcriptionally to promote stress responses.

GCN2 is often misleadingly called an "amino acid sensor" as GCN2 is rapidly activated in response to amino acid deprivation and mediates starvation responses in diverse eukaryotes $[39,40]$. Early studies confirmed that GCN2 does not directly sense amino acids and hypothesized that GCN2 senses uncharged tRNAs (i.e., tRNAs that have not been ligated with an amino acid by an aminoacyl-tRNA synthetase, presumably due to amino acid deprivation), and that physical interaction with uncharged tRNAs allosterically activates GCN2 [40-43]. Later studies upended this straightforward model, proposing instead that GCN2 senses translational stress through alternative mechanisms, such as by directly binding the exposed phosphoprotein (P)-stalk of stalled mRNA-bound ribosomes $[44,45]$ or by acting as a transducer downstream of other proteins that associate with stalled ribosomes $[46,47]$. While the distinction among directly sensing uncharged tRNAs, directly sensing exposed P-stalks, and acting as a transducer for other sensors of translational stress seems esoteric, these distinctions are critical for understanding human diseases [48]. In mouse, Drosophila, and human cell models of Charcot-Marie-Tooth (CMT) disease, a genetic disorder that causes peripheral neuropathies, tRNA synthetases carry partially dysfunctional mutations that limit the synthesis of charged tRNAs, leading to translational stress and constitutive activation of GCN2 [48-51]. Overexpressing tRNA genes reduces CMT symptoms and suppresses GCN2 by increasing levels of both charged tRNAs and uncharged tRNAs [49,51]. This experiment in a disease model demonstrates that accumulation of uncharged tRNAs is not sufficient to activate GCN2 in cells. Therefore, structural, biochemical, and in vivo experiments indicate that GCN2 is not an amino acid sensor or an uncharged tRNA sensor but is most likely a sensor or transducer of translational stress per se in eukaryotic cells $[46,47,52]$ (Figure 1). 

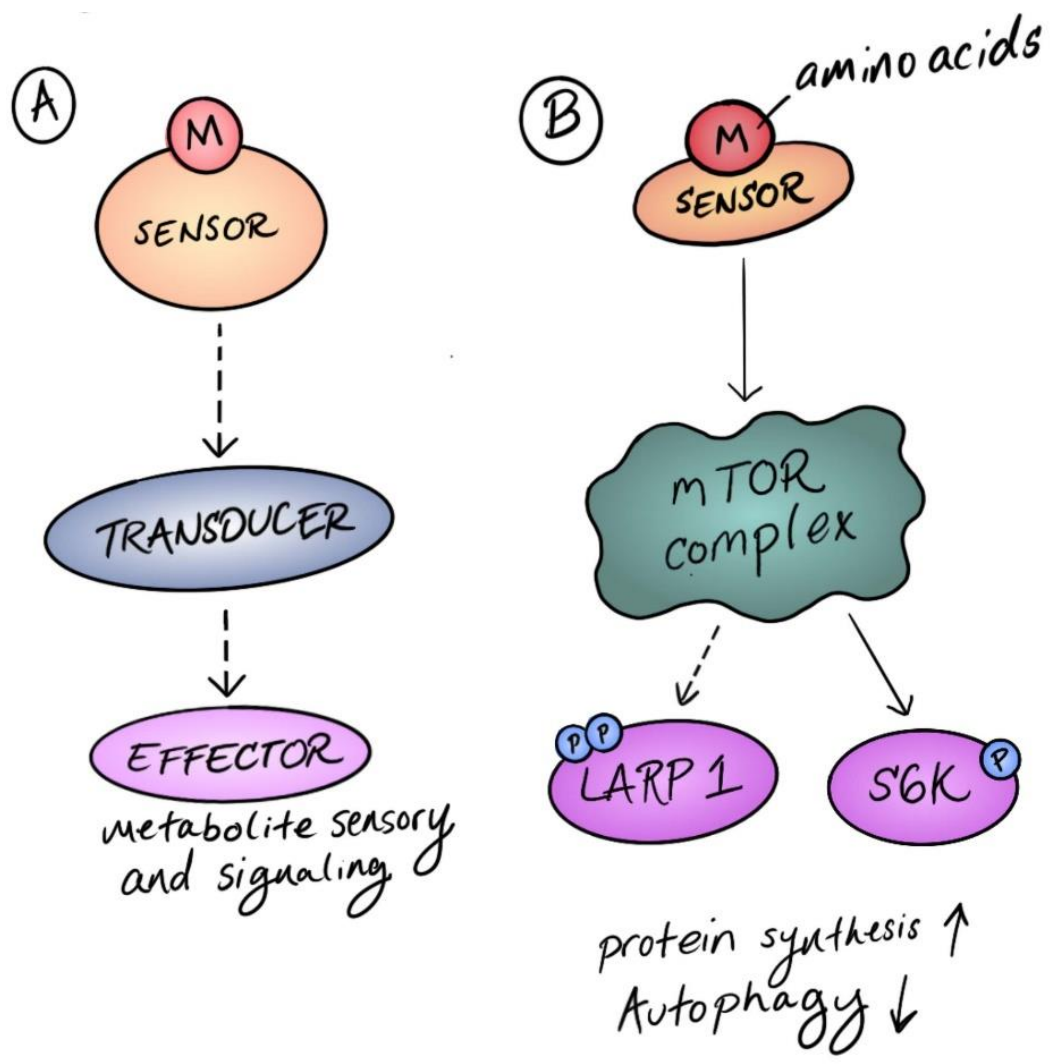

Figure 1. Sensors and transducers in metabolic signaling. (A) Metabolic signaling is triggered by a metabolite sensor protein that directly binds to a metabolite. The sensor then engages transducers in a signaling pathway that eventually activate responses through an effector protein. (B) In mammalian models, amino acids are sensed directly by diverse sensor proteins that activate the mechanistic target of rapamycin (mTOR), a central regulatory hub that transduces diverse upstream signals to coordinate metabolism. mTOR then phosphorylates additional transducers and effectors, such as LARP1 and S6K, to promote protein synthesis and repress autophagy.

\section{The Growing Chorus of Amino Acid Sensors and Transducers for Mammalian TOR}

From an evolutionary perspective, sensors may evolve through one of two general mechanisms: exaptation or adaptation [2]. In the former case, a sensor evolves from a protein that already interacted with the cue it senses (e.g., an enzyme and its substrate), later evolving to interact with a transducer that connects to a downstream signal transduction pathway. This situation is called "exaptation" [53] because both the transduction pathway and the sensor already existed in cells, and they were co-opted to create a new pathway that conferred some fitness benefit. When the sensor retains its ancestral function in addition to its new, exaptive role as a sensor, the sensor is often called a "moonlighting protein". In the latter case, an existing transducer or sensor evolves the capacity to sense a new cue. This situation is called "adaptation" because the sensor did not already interact with a cue but arose de novo through mutation of a previously nonsensor protein and conferred some fitness benefit. The distinction between exaptation and adaptation is useful for understanding the evolutionary origins and diversity of amino acid sensors in eukaryotic cells.

We now present the major proposed amino acid sensors for TOR and discuss their proposed transducers that mediate the signaling pathway to TOR. In mammals, TOR is especially responsive to levels of the essential amino acid leucine (Leu) and the conditionally essential amino acid arginine (Arg) [54,55]. Leucyl-tRNA synthetase (LARS) was the first proposed leucine sensor for TOR, identified through a protein-protein interaction screen for potential amino acid sensors in yeast [56] and through colocalization experiments in mammalian cells [57]. SLC38A9, an amino acid transporter localized to the membranes 
of lysosomes (lytic vacuoles), was the first proposed arginine sensor for TOR, identified through a protein-protein interaction screen for potential amino acid sensors in mammals [58]. Both LARS and SLC38A9 are examples of exaptation as their ancestral functions already involved direct interactions with leucine and Arg, respectively, at a molecular level.

Protein-protein interaction screens later identified additional amino acid sensors for TOR in mammalian cells, including the leucine sensors Sestrin1/2 [59,60] and Sar1b [61], the arginine sensor Castor1 $[62,63]$, and a sensor of the methionine derivative S-adenosyl methionine (SAM) called SAMTOR [64]. Sestrins have an ancestral role as transducers of stress signals to TOR $[2,65]$ : Sestrin genes are transcriptionally activated by stress-responsive transcription factors, including p53 and the GCN2-stimulated activating transcription factor 4 (ATF4). Very recently in the mammalian lineage, some Sestrins evolved a leucinebinding pocket that induces a conformational change to prevent their role in transducing stress signals to TOR. In humans, not all Sestrin paralogues interact with leucine (for example, Sestrin3 is completely leucine-insensitive), and Sestrin orthologues outside of mammals do not include a leucine-binding site, suggesting that the leucine sensor function of Sestrin $1 / 2$ is a recent adaptation and that Sestrin genes are subfunctionalizing in the human lineage [65]. Sar1b is a small GTPase in the Arf family, which is conserved across eukaryotes and participates in endomembrane trafficking. Human and C. elegans Sar1b orthologues directly bind to leucine and signal leucine levels to TOR through interaction with transducers [61]. Whether Sar1b orthologues in other lineages bind to leucine is not established, but presumably, the role of Sar1b as a leucine sensor is another example of adaptation. The evolutionary histories of Castor1 and SAMTOR are less clear; Castor1 encodes two ACT domains, which are found in various metabolite-binding proteins and enzymes [66], and SAMTOR likely evolved from a SAM-dependent methyltransferase or may itself be a functional SAM-dependent methyltransferase enzyme [64]. Neither gene has readily identifiable orthologues outside of vertebrates, suggesting that these sensors evolved very recently in the human lineage.

The transducers of amino acid signals to TOR were largely identified before the amino acid sensors, primarily through screens for protein interactors of TOR and associated proteins, but also through genetic screens for regulators of TOR activity. The Rag family of small GTPases forms a complex with regulatory proteins called the "Ragulator", which forms a platform for the activation of TOR at the surface of lysosomes [67]. These Rag GTPases are regulated by the "GAP activity towards the Rags 1" (GATOR1) complex, which stimulates hydrolysis of RagA/RagB-bound GTP to negatively regulate TOR [68-70]. GATOR1 is negatively regulated by another multiprotein complex, GATOR2. GATOR2 transduces signals from Sestrins, Castor1, and Sar1b; GATOR1 transduces these signals along with signals from SAMTOR; and the Ragulator complex transduces all these signals along with signals from SLC38A9 and LARS (Figure 2).

Multiple groups proposed that the diversity of amino acid sensors in mammalian cells reflects functional differences rather than simple redundancy $[23,61]$. The proposed sensors have distinct binding affinities, subcellular localizations, and expression profiles, and sensors intersect with distinct transducers upstream of TOR, which conceivably allows the various sensors to coordinately act on TOR like "rheostats" that fine-tune TOR activity in response to dynamic metabolic conditions [1]. To illustrate, Castor1 and SLC38A9 are localized to the cytosol and lysosome, respectively, responding to different subcellular pools of arginine $[58,62,63,71]$. As another example, Sestrin1, Sestrin2, and Sar1b each bind specifically to leucine in the cytosol, but with high, moderate, and low affinities, respectively $[59,61]$. In cells that express both Sestrins and Sar1b, Sestrins engage with GATOR2 and only partially suppress TOR activity when leucine levels are moderately low, but both Sar1b and Sestrins engage with GATOR2 and completely inactivate TOR when leucine is extremely scarce or absent [61]. 

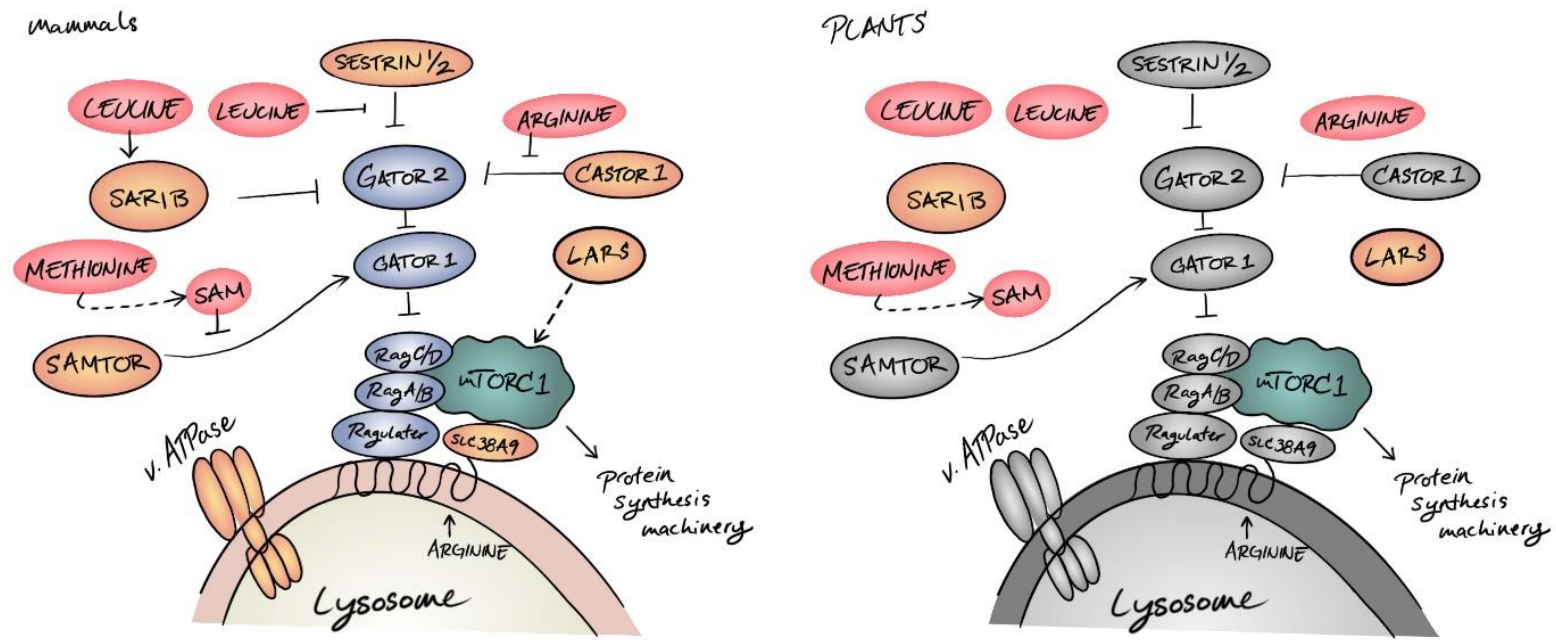

Figure 2. Amino acid signaling in eukaryotes. In mammals, amino acids (red) are monitored by multiple sensors (orange) that engage transducers (blue) at multiple steps in the GATOR2-GATOR1Ragulator-Rag GTPase signaling cascade to coordinate TOR (teal) activity at the surface of the lysosome. Very few of these signaling components are conserved in plants (gray indicates not conserved in plants). Sar1b and LARS, which have essential roles in membrane trafficking and tRNA synthesis, respectively, were exapted as amino acid sensors in the animal lineage and may not act as amino acid sensors in plants.

Beyond leucine and arginine, many other amino acids stimulate TOR, and the potency of TOR activation by specific amino acids varies across biological contexts (e.g., cell type, species, experimental conditions, etc.). Some of these amino acid sensitivities are mediated by the GATOR2-GATOR1-Ragulator transduction pathway, but others act independently. For example, glutamine and asparagine activate TOR through Ragulator-independent mechanisms [72,73]. The details of how glutamine and asparagine activate TOR are still under investigation, but several studies have pointed to the role of another small GTPase, Arf1, in transducing glutamine and asparagine signals to TOR [74]. Alternative (but not mutually exclusive) pathways have been proposed, including that glutamine drives synthesis of $\alpha$-ketoglutarate ( $\alpha \mathrm{KG}$, also known as 2-oxoglutarate or 2OG) via glutaminolysis, and that $\alpha \mathrm{KG}$ promotes TOR activity in Ragulator-dependent mechanisms [75]; or, that glutamine and asparagine elevate ATP / AMP ratios via asparagine synthase and the GABA shunt, which, in turn, inhibits the TOR-antagonizing AMP-activated kinase (AMPK) [75]. Therefore, glutamine and asparagine may activate TOR indirectly, without any glutamineor asparagine-specific sensor proteins in cells.

Leu may induce TOR indirectly, without a bona fide Leu sensor, under some circumstances. In cells that do not strongly express Sestrins, including HeLa cells, Leu stimulates TOR through a downstream metabolite, acetyl coenzyme A (AcCoA) [76,77]. AcCoA is synthesized in human cells from pyruvate, fatty acid, or branched-chain amino acid (especially Leu) precursors [78]. Under leucine deprivation, AcCoA levels temporarily decrease, but they can be restored by resupplying leucine or by compensatory synthesis from other precursors [76]. AcCoA is mobilized in the cytosol to acetylate the TOR-associated protein RAPTOR, which effectively increases TOR activity in cells; RAPTOR acetylation correlates tightly with cytosolic AcCoA concentrations, thereby acting as an AcCoA sensor [77]. Knocking down Sestrin $1 / 2$ or LARS does not prevent leucine from activating TOR in some cell types (e.g., HeLa cells), but knocking down the enzymes that metabolize leucine to produce AcCoA makes TOR unresponsive to leucine supply $[76,77]$. This discovery illustrates the complexity of amino acid signaling in cells and highlights how TOR can integrate multiple dynamic cues as the hub of a signal transduction network. 


\section{Plant Nutrient Sensing: From Inorganic Precursors to Organic Metabolites}

Most investigations relevant to plant amino acid signaling have focused on how upstream precursors are sensed by plant cells, including inorganic nutrients absorbed from soil (e.g., nitrate, ammonium, and sulfate) and photosynthesis-related cues (carbon dioxide, light, and sugars). The best-studied sensor of nitrogenous nutrients in plant cells is the plasma-membrane-localized nitrate transporter 1.1 (NRT1.1, often called chlorina 1 or CHL1), a transceptor that alters nuclear gene expression when it detects environmental nitrate via a calcium-dependent protein kinase signaling cascade [79-81]. Pioneering studies of plant TOR signaling focused on how TOR reacts to photosynthesized sugars rather than amino acids. In plant cells, sugars are directly sensed by proteins including hexokinase (HXK1) and the SNF1-related protein kinase (SnRK1, orthologous to human AMP-activated kinase, AMPK, but not sensitive to AMP or ATP) [82]. HXK1 evolved an exaptive signaling role in addition to its critical metabolic function in glycolysis, signaling sugar availability in response to direct interaction with glucose [83-85]. SnRK1 phosphorylates proteins to promote stress and starvation responses but is repressed by a proposed direct interaction with trehalose-6-phosphate, an intermediate in sugar metabolism [86-89]. Although TOR activity is likely regulated by SnRK1 [90], sugar activation of TOR also requires glycolysis and oxidative phosphorylation [91,92], suggesting that TOR responds primarily to ATP levels rather than directly to sugars. This may be analogous to the mammalian model: TOR senses glycolytic intermediates (dihydroxyacetone phosphate), but only in cells that lack ATP-sensing pathways [93]. Although no ATP sensors are established in plant cells, a proposed ATP sensor for mammalian TOR, the cochaperone R2TP ATPase complex, is conserved in plants and regulates TOR activity, hinting that R2TP may be an ATP sensor in plant cells [94,95].

Several forward genetic screens have refocused attention on how plants sense organic nitrogenous nutrients, especially amino acids and nucleotides. Two independent genetic screens for Arabidopsis thaliana mutants that disrupt cellular patterning identified recessive alleles of isopropyl malate synthase 1 (IPMS1), which encodes an enzyme in the leucine biosynthetic pathway $[27,28]$. These ipms 1 mutants display defects in cytoskeletal organization and leaf shape during early seedling development [28], and ipms1 resolves the root hair abnormalities observed in leucine-rich receptor/extensin 1 (lrx1) mutants [27]. Moreover, ipms1 mutants exhibit elevated TOR activity, can be partially phenotypically rescued by very low concentrations of TOR inhibitors, and are resistant to the growth-inhibiting effects of moderate concentrations of TOR inhibitors [28]. Therefore, the effects of ipms1 on amino acid metabolism are somehow transduced to TOR, and this is likely the primary cause of ipms1 cellular and developmental phenotypes. A functional genetic screen for Nicotiana benthamiana genes that regulate TOR activity identified phosphoribosyl pyrophosphate synthetase 4 (PRS4), which encodes an enzyme required for nucleotide biosynthesis in plant cells [13]. Plant TOR senses purine and pyrimidine availability, analogous to how mammalian TOR monitors nucleotide levels $[13,20]$. Thus, plant TOR reacts to disruptions in organic nutrient levels and biosynthetic pathways, but the sensors and transducers involved remain enigmatic (Figure 3).

Beyond plants, the intersecting roles of nutrient sensing, amino acid metabolism, and TOR signaling in distantly related microalgae, such as the chlorophyte Chlamydomonas reinhardtii, are currently under investigation and have potential industrial applications. Several algae are excellent sources of triacylglycerols (TAGs) that could serve as biofuel feedstocks for a sustainable energy future [96], and inhibiting TOR is sufficient to significantly induce TAG biogenesis in candidate biofuel species, including C. reinhardtii and A. thatiana and the nongreen algae Cyanidioschyzon merolae and Phaeodactylum tricornutum [97-101]. Alongside TAG accumulation, inhibiting TOR rapidly increases amino acid levels in C. reinhardtii cells [102]. Metabolomic investigations of the origin of these amino acids found that amino acid accumulation upon TOR inhibition in C. reinhardtii is not primarily due to suppression of mRNA translation or autophagic recycling of proteins but instead due to drastically elevated inorganic nitrogen uptake from the environment and subsequent de novo amino acid 
biosynthesis [103]. As TOR activity is stimulated by both nitrogen and carbon sources in C. reinhardtii cells [104], a possible model is that TOR monitors intracellular nutrient status to regulate extracellular nutrient uptake and maintain carbon/nitrogen balance [102-104]. Understanding how algal cells monitor nutrient status on a molecular scale may accelerate efforts to engineer algae for efficient biofuel production, but very little is known about the mechanisms of nutrient sensing or which nutrients are sensed (inorganic nutrients or organic forms such as amino acids) in these species.

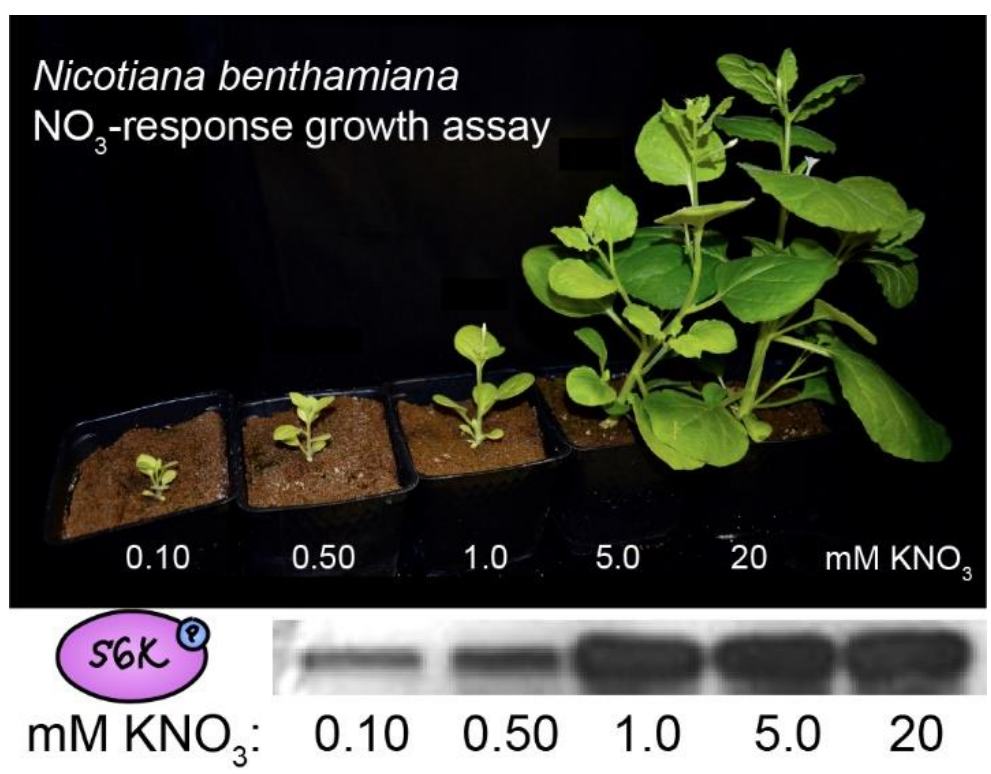

Figure 3. TOR monitors nitrogenous nutrient availability in plants. Plants can synthesize all 20 proteinogenic amino acids from inorganic precursors (nitrate or ammonium, carbon dioxide, and sulfate). $N$. benthamiana were grown on calcined clay and supplied with standard nutrients except for nitrogen, which was supplied as potassium nitrate at the indicated concentrations. Nitrate strongly stimulated plant growth and activated TOR, as measured by Western blots using phosphospecific antibodies against the canonical TOR substrate, S6K-pT449 (methods as in [13]).

A major outstanding question in plant metabolic signaling is whether plant cells encode true amino acid sensors analogous to the aforementioned mammalian amino acid sensors for TOR. Amino acid profiles of ipms1 mutants, which show constitutively elevated TOR activity, revealed altered levels of almost every amino acid except for lysine and methionine [28]. The relative potency of TOR activation by amino acids was not clearly resolved by experiments using other mutants in the branched-chain amino acid biosynthetic pathway [28]. In leaf discs floated on solutions containing either isoleucine or glutamine at night, TOR activity was rapidly induced [29]; no amino acids were conclusively shown to be incapable of activating TOR, but glutamine had a stronger effect on TOR activity than isoleucine [29]. In Arabidopsis seedlings grown for 9 days without any source of nitrogen, TOR became inactive and growth was arrested. Supplying most amino acids to these nitrogen-starved seedlings activated TOR within minutes, except for arginine, proline, and the aromatic amino acids phenylalanine, tryptophan, and tyrosine [30]. Nitrate and ammonium may also activate TOR in this experimental system, even in the presence of tungstate (a nitrate reductase inhibitor) or methionine sulfoximine (a glutamine synthetase inhibitor), which prevent the assimilation of nitrogen into amino acids [30]. This may suggest that TOR specifically senses inorganic forms of nitrogen in plants and that amino acids supplied to $\mathrm{N}$-deprived seedlings are catabolized to yield inorganic nitrogen forms. Alternatively, plant TOR may monitor multiple nitrogenous cues, including inorganic nitrogen and diverse amino acids, analogous to the diversity of amino acids and amino acid related metabolites sensed by mammalian TOR. To summarize, although current data 
do not resolve whether plant cells directly sense amino acid cues, TOR dynamically reacts to changes in amino acid metabolism (Figure 4).

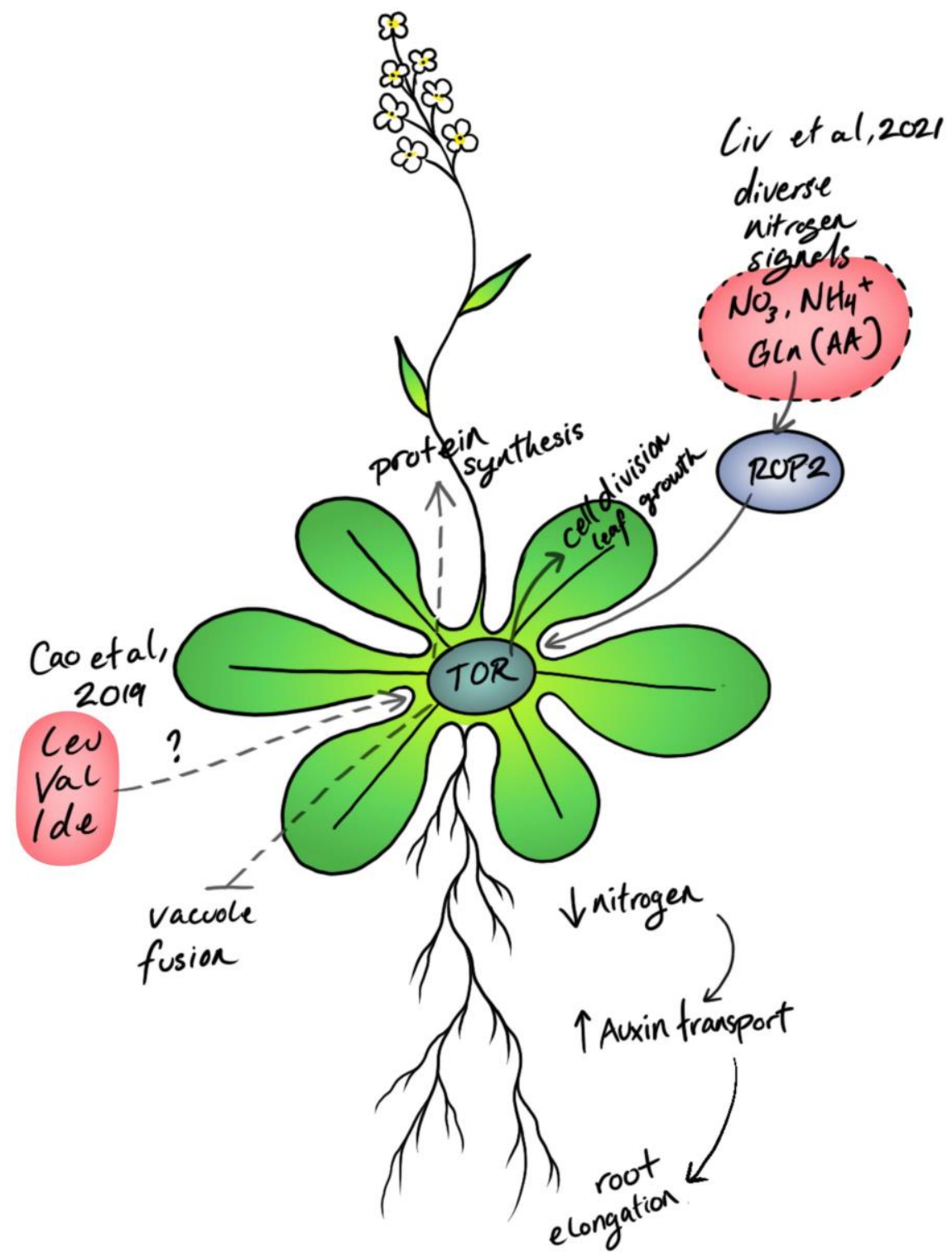

Figure 4. TOR responds to nitrogen and amino acid metabolism in plants to coordinate growth and development [30], protein synthesis [6], and cytoskeletal function [27,28].

\section{The Future of Crops: Deploying TOR for a Sustainable Agricultural Future}

Modern agriculture relies heavily on inorganic fertilizers to drive growth and increase yields [105,106]. Fertilizers are primarily composed of ammonias to provide nitrogen (e.g., ammonium nitrate), phosphate rock to provide phosphorus, and potash to provide potassium. Crops use fertilizers inefficiently, resulting in significant fertilizer run-off that is environmentally disruptive [26,107]. Moreover, fertilizers are nonrenewable resources: potash and phosphate rock are both ores mined from limited underground sources. Most studies agree that both potash and phosphate production will peak in the 21st century, reducing fertilizer availability while agriculture faces other pressures from changing climates, dwindling arable land, and growing global populations [108,109]. Therefore, a goal of plant biology in the 21st century is to reduce reliance on external fertilizer sources and maximize nutrient use efficiency in diverse, resilient crop species.

We argue that a detailed mechanistic understanding of the TOR signaling network in plants is critical for these efforts. By defining the nutrient sensors and signaling network 
transducers that act upstream of TOR and the phosphoprotein effectors and downstream processes engaged by TOR, we expect to discover new targets for breeding, biotechnological interventions, or both to improve plant nutrient use efficiency. Whereas TOR signaling networks evolved to maintain homeostasis for plants that experience unpredictable, fluctuating environments in ecological competition with other plant species, domesticated crops do not face these same fitness costs and selective pressures. Ongoing investigations of TOR signaling in model systems, including Arabidopsis, may illuminate new targets for genetic modification, contributing to the larger project of establishing a sustainable global agricultural program.

Author Contributions: N.L. and J.O.B. contributed equally to the conceptualization, writing, and preparation of the manuscript. All authors have read and agreed to the published version of the manuscript.

Funding: This project was funded by a U.S. National Institutes of Health grant (grant number: NIH DP5-OD023072) to J.O.B. and a U.S. National Science Foundation (NSF) graduate research fellowship under Grant No. 1752814 to Nanticha Lutt.

Acknowledgments: We thank Shivani Upadhyaya for contributing to helpful discussions during the preparation of this manuscript.

Conflicts of Interest: The authors declare no conflict of interest.

\section{References}

1. Valvezan, A.J.; Manning, B.D. Molecular logic of mTORC1 signalling as a metabolic rheostat. Nat. Metab. 2019, 1, 321-333. [CrossRef] [PubMed]

2. Brunkard, J.O. Exaptive Evolution of Target of Rapamycin Signaling in Multicellular Eukaryotes. Dev. Cell 2020, 54, 142-155. [CrossRef] [PubMed]

3. Liu, G.Y.; Sabatini, D.M. mTOR at the nexus of nutrition, growth, ageing and disease. Nat. Rev. Mol. Cell Biol. 2020, 21, 183-203. [CrossRef] [PubMed]

4. Shi, L.; Wu, Y.; Sheen, J. TOR signaling in plants: Conservation and innovation. Development 2018, 145, dev160887. [CrossRef] [PubMed]

5. Burkart, G.M.; Brandizzi, F. A Tour of TOR Complex Signaling in Plants. Trends Biochem. Sci. 2021, 46, 417-428. [CrossRef] [PubMed]

6. Scarpin, M.R.; Leiboff, S.; Brunkard, J.O. Parallel global profiling of plant tor dynamics reveals a conserved role for larp1 in translation. Elife 2020, 9, e58795. [CrossRef]

7. Thomas, G.; Hall, M.N. TOR signalling and control of cell growth. Curr. Opin. Cell Biol. 1997, 9, 782-787. [CrossRef]

8. Thoreen, C.C.; Chantranupong, L.; Keys, H.R.; Wang, T.; Gray, N.S.; Sabatini, D.M. A unifying model for mTORC1-mediated regulation of mRNA translation. Nature 2012, 485, 109-113. [CrossRef]

9. Meyuhas, O.; Kahan, T. The race to decipher the top secrets of TOP mRNAs. Biochim. Biophys. Acta-Gene Regul. Mech. 2015, 1849, 801-811. [CrossRef]

10. Valvezan, A.J.; Turner, M.; Belaid, A.; Lam, H.C.; Miller, S.K.; McNamara, M.C.; Baglini, C.; Housden, B.E.; Perrimon, N.; Kwiatkowski, D.J.; et al. mTORC1 Couples Nucleotide Synthesis to Nucleotide Demand Resulting in a Targetable Metabolic Vulnerability. Cancer Cell 2017, 32, 624-638.e5. [CrossRef]

11. Robitaille, A.M.; Christen, S.; Shimobayashi, M.; Cornu, M.; Fava, L.L.; Moes, S.; Prescianotto-Baschong, C.; Sauer, U.; Jenoe, P.; Hall, M.N. Quantitative phosphoproteomics reveal mTORC1 activates de novo pyrimidine synthesis. Science 2013, 339, 1320-1323. [CrossRef] [PubMed]

12. Ben-Sahra, I.; Howell, J.J.; Asara, J.M.; Manning, B.D. Stimulation of de novo pyrimidine synthesis by growth signaling through mTOR and S6K1. Science 2013, 339, 1323-1328. [CrossRef] [PubMed]

13. Busche, M.; Scarpin, M.R.; Hnasko, R.; Brunkard, J.O. TOR coordinates nucleotide availability with ribosome biogenesis in plants. Plant Cell 2021, 33, 1615-1632. [CrossRef] [PubMed]

14. Düvel, K.; Yecies, J.L.; Menon, S.; Raman, P.; Lipovsky, A.I.; Souza, A.L.; Triantafellow, E.; Ma, Q.; Gorski, R.; Cleaver, S.; et al. Activation of a Metabolic Gene Regulatory Network Downstream of mTOR Complex 1. Mol. Cell 2010, 39, 171-183. [CrossRef]

15. Laplante, M.; Sabatini, D.M. An Emerging Role of mTOR in Lipid Biosynthesis. Curr. Biol. 2009, 19, R1046-R1052. [CrossRef]

16. Thelen, A.M.; Zoncu, R. Emerging Roles for the Lysosome in Lipid Metabolism. Trends Cell Biol. 2017, 27, 833-850. [CrossRef]

17. Kamada, Y.; Funakoshi, T.; Shintani, T.; Nagano, K.; Ohsumi, M.; Ohsumi, Y. Tor-Mediated Induction of Autophagy via an Apg1 Protein Kinase Complex. J. Cell Biol. 2000, 150, 1507-1513. [CrossRef]

18. Kim, J.; Kundu, M.; Viollet, B.; Guan, K.L. AMPK and mTOR regulate autophagy through direct phosphorylation of Ulk1. Nat. Cell Biol. 2011, 13, 132-141. [CrossRef]

19. Liu, Y.; Bassham, D.C. TOR Is a Negative Regulator of Autophagy in Arabidopsis thaliana. PLoS ONE 2010, 5, e11883. [CrossRef] 
20. Kazibwe, Z.; Soto-Burgos, J.; MacIntosh, G.C.; Bassham, D.C. TOR mediates the autophagy response to altered nucleotide homeostasis in an RNase mutant. J. Exp. Bot. 2020, 71, 6907-6920. [CrossRef]

21. Noda, T. Regulation of Autophagy through TORC1 and mTORC1. Biomolecules 2017, 7, 52. [CrossRef] [PubMed]

22. Masvidal, L.; Hulea, L.; Furic, L.; Topisirovic, I.; Larsson, O. mTOR-sensitive translation: Cleared fog reveals more trees. RNA Biol. 2017, 14, 1299-1305. [CrossRef] [PubMed]

23. Wolfson, R.L.; Sabatini, D.M. The Dawn of the Age of Amino Acid Sensors for the mTORC1 Pathway. Cell Metab. 2017, 26, 301-309. [CrossRef] [PubMed]

24. Maeda, H.; Dudareva, N. The Shikimate Pathway and Aromatic Amino Acid Biosynthesis in Plants. Annu. Rev. Plant Biol. 2012, 63, 73-105. [CrossRef] [PubMed]

25. Binder, S. Branched-Chain Amino Acid Metabolism in Arabidopsis thaliana. Arab. B. 2010, 8, e0137. [CrossRef]

26. Xu, G.; Fan, X.; Miller, A.J. Plant Nitrogen Assimilation and Use Efficiency. Annu. Rev. Plant Biol. 2012, 63, 153-182. [CrossRef]

27. Schaufelberger, M.; Galbier, F.; Herger, A.; De Brito Francisco, R.; Roffler, S.; Clement, G.; Diet, A.; Hörtensteiner, S.; Wicker, T.; Ringli, C. Mutations in the Arabidopsis ROL17/isopropylmalate synthase 1 locus alter amino acid content, modify the TOR network, and suppress the root hair cell development mutant lrx1. J. Exp. Bot. 2019, 70, 2313-2323. [CrossRef]

28. Cao, P.; Kim, S.J.; Xing, A.; Schenck, C.A.; Liu, L.; Jiang, N.; Wang, J.; Last, R.L.; Brandizzi, F. Homeostasis of branched-chain amino acids is critical for the activity of TOR signaling in Arabidopsis. Elife 2019, 8, e50747. [CrossRef]

29. O'Leary, B.M.; Oh, G.G.K.; Lee, C.P.; Millar, A.H. Metabolite Regulatory Interactions Control Plant Respiratory Metabolism via Target of Rapamycin (TOR) Kinase Activation. Plant Cell 2020, 32, 666-682. [CrossRef]

30. Liu, Y.; Duan, X.; Zhao, X.; Ding, W.; Wang, Y.; Xiong, Y. Diverse nitrogen signals activate convergent ROP2-TOR signaling in Arabidopsis. Dev. Cell 2021, 56, 1283-1295.e5. [CrossRef]

31. Vellai, T. How the amino acid leucine activates the key cell-growth regulator mTOR. Nature 2021, 596, 192-194. [CrossRef] [PubMed]

32. Ulijasz, A.T.; Cornilescu, G.; Cornilescu, C.C.; Zhang, J.; Rivera, M.; Markley, J.L.; Vierstra, R.D. Structural basis for the photoconversion of a phytochrome to the activated Pfr form. Nature 2010, 463, 250-254. [CrossRef] [PubMed]

33. Webb, A.A.R.; Kuchitsu, K.; Kwak, J.; Pei, Z.-M.; Iida, H. Sensors Make Sense of Signaling. Plant Cell Physiol. 2017, 58, 1121-1125. [CrossRef]

34. Dever, T.E.; Feng, L.; Wek, R.C.; Cigan, A.M.; Donahue, T.F.; Hinnebusch, A.G. Phosphorylation of initiation factor $2 \alpha$ by protein kinase GCN2 mediates gene-specific translational control of GCN4 in yeast. Cell 1992, 68, 585-596. [CrossRef]

35. Lageix, S.; Lanet, E.; Pouch-Pélissier, M.N.; Espagnol, M.C.; Robaglia, C.; Deragon, J.M.; Pélissier, T. Arabidopsis eIF2 $\alpha$ kinase GCN2 is essential for growth in stress conditions and is activated by wounding. BMC Plant Biol. 2008, 8, 134. [CrossRef]

36. Chikashige, Y.; Kato, H.; Thornton, M.; Pepper, W.; Hilgers, M.; Cecil, A.; Asano, I.; Yamada, H.; Mori, C.; Brunkow, C.; et al. Gen2 eIF $2 \alpha$ kinase mediates combinatorial translational regulation through nucleotide motifs and uORFs in target mRNAs. Nucleic Acids Res. 2020, 48, 8977-8992. [CrossRef] [PubMed]

37. Zhang, Y.; Wang, Y.; Kanyuka, K.; Parry, M.A.J.; Powers, S.J.; Halford, N.G. GCN2-dependent phosphorylation of eukaryotic translation initiation factor-2 $\alpha$ in Arabidopsis. J. Exp. Bot. 2008, 59, 3131-3141. [CrossRef]

38. Tzamarias, D.; Thireos, G. Evidence that the GCN2 protein kinase regulates reinitiation by yeast ribosomes. EMBO J. 1988, 7 , 3547-3551. [CrossRef]

39. Costa-Mattioli, M.; Walter, P. The integrated stress response: From mechanism to disease. Science 2020, 368, eaat5314. [CrossRef]

40. Li, M.W.; Auyeung, W.K.; Lam, H.M. The GCN2 homologue in Arabidopsis thaliana interacts with uncharged tRNA and uses Arabidopsis eIF $2 \alpha$ molecules as direct substrates. Plant Biol. 2013, 15, 13-18. [CrossRef]

41. Wek, S.A.; Zhu, S.; Wek, R.C. The histidyl-tRNA synthetase-related sequence in the eIF-2 alpha protein kinase GCN2 interacts with tRNA and is required for activation in response to starvation for different amino acids. Mol. Cell. Biol. 1995, 15, 4497-4506 [CrossRef] [PubMed]

42. Dong, J.; Qiu, H.; Garcia-Barrio, M.; Anderson, J.; Hinnebusch, A.G. Uncharged tRNA activates GCN2 by displacing the protein kinase moiety from a bipartite tRNA-binding domain. Mol. Cell 2000, 6, 269-279. [CrossRef]

43. Wek, R.C.; Jackson, B.M.; Hinnebusch, A.G. Juxtaposition of domains homologous to protein kinases and histidyl-tRNA synthetases in GCN2 protein suggests a mechanism for coupling GCN4 expression to amino acid availability. Proc. Natl. Acad. Sci. USA 1989, 86, 4579-4583. [CrossRef] [PubMed]

44. Harding, H.P.; Ordonez, A.; Allen, F.; Parts, L.; Inglis, A.J.; Williams, R.L.; Ron, D. The ribosomal P-stalk couples amino acid starvation to GCN2 2 activation in mammalian cells. Elife 2019, 8, e50149. [CrossRef] [PubMed]

45. Inglis, A.J.; Masson, G.R.; Shao, S.; Perisic, O.; McLaughlin, S.H.; Hegde, R.S.; Williams, R.L. Activation of GCN2 by the ribosomal P-stalk. Proc. Natl. Acad. Sci. USA 2019, 116, 4946-4954. [CrossRef] [PubMed]

46. Wu, C.C.-C.; Peterson, A.; Zinshteyn, B.; Regot, S.; Green, R. Ribosome Collisions Trigger General Stress Responses to Regulate Cell Fate. Cell 2020, 182, 404-416.e14. [CrossRef]

47. Pochopien, A.A.; Beckert, B.; Kasvandik, S.; Berninghausen, O.; Beckmann, R.; Tenson, T.; Wilson, D.N. Structure of Gcn1 bound to stalled and colliding 80 S ribosomes. Proc. Natl. Acad. Sci. USA 2021, 118, e2022756118. [CrossRef]

48. Mellado, W.; Willis, D.E. Stressing out translation. Science 2021, 373, 1089-1090. [CrossRef] 
49. Zuko, A.; Mallik, M.; Thompson, R.; Spaulding, E.L.; Wienand, A.R.; Been, M.; Tadenev, A.L.D.; van Bakel, N.; Sijlmans, C.; Santos, L.A.; et al. tRNA overexpression rescues peripheral neuropathy caused by mutations in tRNA synthetase. Science 2021, 373, 1161-1166. [CrossRef]

50. Spaulding, E.L.; Hines, T.J.; Bais, P.; Tadenev, A.L.D.; Schneider, R.; Jewett, D.; Pattavina, B.; Pratt, S.L.; Morelli, K.H.; Stum, M.G.; et al. The integrated stress response contributes to tRNA synthetase-associated peripheral neuropathy. Science 2021, 373, 1156-1161. [CrossRef]

51. Mendonsa, S.; von Kuegelgen, N.; Bujanic, L.; Chekulaeva, M. Charcot-Marie-Tooth mutation in glycyl-tRNA synthetase stalls ribosomes in a pre-accommodation state and activates integrated stress response. Nucleic Acids Res. 2021, 49, 10007-10017. [CrossRef] [PubMed]

52. Brunkard, J.O.; Baker, B. A two-headed monster to avert disaster: HBS1/SKI7 is alternatively spliced to build eukaryotic RNA surveillance complexes. Front. Plant Sci. 2018, 9, 1333. [CrossRef] [PubMed]

53. Gould, S.J.; Vrba, E.S. Exaptation-A Missing Term in the Science of Form. Paleobiology 1982, 1, 4-15. [CrossRef]

54. Ban, H.; Shigemitsu, K.; Yamatsuji, T.; Haisa, M.; Nakajo, T.; Takaoka, M.; Nobuhisa, T.; Gunduz, M.; Tanaka, N.; Naomoto, Y. Arginine and Leucine regulate p70 S6 kinase and 4E-BP1 in intestinal epithelial cells. Int. J. Mol. Med. 2004, 13, 537-543. [CrossRef]

55. Stipanuk, M.H. Leucine and Protein Synthesis: mTOR and Beyond. Nutr. Rev. 2008, 65, 122-129. [CrossRef]

56. Bonfils, G.; Jaquenoud, M.; Bontron, S.; Ostrowicz, C.; Ungermann, C.; De Virgilio, C. Leucyl-tRNA Synthetase Controls TORC1 via the EGO Complex. Mol. Cell 2012, 46, 105-110. [CrossRef]

57. Han, J.M.; Jeong, S.J.; Park, M.C.; Kim, G.; Kwon, N.H.; Kim, H.K.; Ha, S.H.; Ryu, S.H.; Kim, S. Leucyl-tRNA synthetase is an intracellular leucine sensor for the mTORC1-signaling pathway. Cell 2012, 149, 410-424. [CrossRef]

58. Wang, S.; Tsun, Z.Y.; Wolfson, R.L.; Shen, K.; Wyant, G.A.; Plovanich, M.E.; Yuan, E.D.; Jones, T.D.; Chantranupong, L.; Comb, W.; et al. Lysosomal amino acid transporter SLC38A9 signals arginine sufficiency to mTORC1. Science 2015, 347, 188-194. [CrossRef]

59. Wolfson, R.L.; Chantranupong, L.; Saxton, R.A.; Shen, K.; Scaria, S.M.; Cantor, J.R.; Sabatini, D.M. Sestrin2 is a leucine sensor for the mTORC1 pathway. Science 2016, 351, 43-48. [CrossRef]

60. Saxton, R.A.; Knockenhauer, K.E.; Wolfson, R.L.; Chantranupong, L.; Pacold, M.E.; Wang, T.; Schwartz, T.U.; Sabatini, D.M Structural basis for leucine sensing by the Sestrin2-mTORC1 pathway. Science 2016, 351, 53-58. [CrossRef]

61. Chen, J.; Ou, Y.; Luo, R.; Wang, J.; Wang, D.; Guan, J.; Li, Y.; Xia, P.; Chen, P.R.; Liu, Y. SAR1B senses leucine levels to regulate mTORC1 signalling. Nature 2021, 596, 281-284. [CrossRef] [PubMed]

62. Saxton, R.A.; Chantranupong, L.; Knockenhauer, K.E.; Schwartz, T.U.; Sabatini, D.M. Mechanism of arginine sensing by CASTOR1 upstream of mTORC1. Nature 2016, 536, 229-233. [CrossRef] [PubMed]

63. Chantranupong, L.; Scaria, S.M.; Saxton, R.A.; Gygi, M.P.; Shen, K.; Wyant, G.A.; Wang, T.; Harper, J.W.; Gygi, S.P.; Sabatini, D.M. The CASTOR Proteins Are Arginine Sensors for the mTORC1 Pathway. Cell 2016, 165, 153-164. [CrossRef] [PubMed]

64. Gu, X.; Orozco, J.M.; Saxton, R.A.; Condon, K.J.; Liu, G.Y.; Krawczyk, P.A.; Scaria, S.M.; Harper, J.W.; Gygi, S.P.; Sabatini, D.M SAMTOR is an S-adenosylmethionine sensor for the mTORC1 pathway. Science 2017, 358, 813-818. [CrossRef]

65. Lee, J.H.; Cho, U.S.; Karin, M. Sestrin regulation of TORC1: Is sestrin a leucine sensor? Sci. Signal. 2016, 9, re5. [CrossRef]

66. Lang, E.J.; Cross, P.J.; Mittelstädt, G.; Jameson, G.B.; Parker, E.J. Allosteric ACTion: The varied ACT domains regulating enzymes of amino-acid metabolism. Curr. Opin. Struct. Biol. 2014, 29, 102-111. [CrossRef]

67. Sancak, Y.; Bar-Peled, L.; Zoncu, R.; Markhard, A.L.; Nada, S.; Sabatini, D.M. Ragulator-rag complex targets mTORC1 to the lysosomal surface and is necessary for its activation by amino acids. Cell 2010, 141, 290-303. [CrossRef]

68. Bar-Peled, L.; Chantranupong, L.; Cherniack, A.D.; Chen, W.W.; Ottina, K.A.; Grabiner, B.C.; Spear, E.D.; Carter, S.L.; Meyerson, M.; Sabatini, D.M. A tumor suppressor complex with GAP activity for the Rag GTPases that signal amino acid sufficiency to mTORC1. Science 2013, 340, 1100-1106. [CrossRef]

69. Shen, K.; Huang, R.K.; Brignole, E.J.; Condon, K.J.; Valenstein, M.L.; Chantranupong, L.; Bomaliyamu, A.; Choe, A.; Hong, C.; $\mathrm{Yu}, \mathrm{Z}$; ; et al. Architecture of the human GATOR1 and GATOR1-Rag GTPases complexes. Nature 2018, 556, 64-69. [CrossRef]

70. Panchaud, N.; Péli-Gulli, M.-P.; De Virgilio, C. Amino Acid Deprivation Inhibits TORC1 Through a GTPase-Activating Protein Complex for the Rag Family GTPase Gtr1. Sci. Signal. 2013, 6, ra42. [CrossRef]

71. Rebsamen, M.; Pochini, L.; Stasyk, T.; De Araújo, M.E.G.; Galluccio, M.; Kandasamy, R.K.; Snijder, B.; Fauster, A.; Rudashevskaya, E.L.; Bruckner, M.; et al. SLC38A9 is a component of the lysosomal amino acid sensing machinery that controls mTORC1. Nature 2015, 519, 477-481. [CrossRef] [PubMed]

72. Hesketh, G.G.; Papazotos, F.; Pawling, J.; Rajendran, D.; Knight, J.D.R.; Martinez, S.; Taipale, M.; Schramek, D.; Dennis, J.W.; Gingras, A.-C. The GATOR-Rag GTPase pathway inhibits mTORC1 activation by lysosome-derived amino acids. Science 2020, 370, 351-356. [CrossRef]

73. Meng, D.; Yang, Q.; Wang, H.; Melick, C.H.; Navlani, R.; Frank, A.R.; Jewell, J.L. Glutamine and asparagine activate mTORC1 independently of Rag GTPases. J. Biol. Chem. 2020, 295, 2890-2899. [CrossRef] [PubMed]

74. Jewell, J.L.; Kim, Y.C.; Russell, R.C.; Yu, F.-X.; Park, H.W.; Plouffe, S.W.; Tagliabracci, V.S.; Guan, K.-L. Differential regulation of mTORC1 by leucine and glutamine. Science 2015, 347, 194-198. [CrossRef] [PubMed]

75. Bodineau, C.; Tomé, M.; Courtois, S.; Costa, A.S.H.; Sciacovelli, M.; Rousseau, B.; Richard, E.; Vacher, P.; Parejo-Pérez, C.; Bessede, E.; et al. Two parallel pathways connect glutamine metabolism and mTORC1 activity to regulate glutamoptosis. Nat. Commun. 2021, 12, 4814. [CrossRef] [PubMed] 
76. Son, S.M.; Park, S.J.; Lee, H.; Siddiqi, F.; Lee, J.E.; Menzies, F.M.; Rubinsztein, D.C. Leucine Signals to mTORC1 via Its Metabolite Acetyl-Coenzyme A. Cell Metab. 2019, 29, 192-201.e7. [CrossRef]

77. Son, S.M.; Park, S.J.; Stamatakou, E.; Vicinanza, M.; Menzies, F.M.; Rubinsztein, D.C. Leucine regulates autophagy via acetylation of the mTORC1 component raptor. Nat. Commun. 2020, 11, 3148. [CrossRef]

78. Mariño, G.; Pietrocola, F.; Eisenberg, T.; Kong, Y.; Malik, S.A.; Andryushkova, A.; Schroeder, S.; Pendl, T.; Harger, A.; Niso-Santano, M.; et al. Regulation of Autophagy by Cytosolic Acetyl-Coenzyme A. Mol. Cell 2014, 53, 710-725. [CrossRef]

79. Ho, C.H.; Lin, S.H.; Hu, H.C.; Tsay, Y.F. CHL1 Functions as a Nitrate Sensor in Plants. Cell 2009, 138, 1184-1194. [CrossRef]

80. Liu, K.; Niu, Y.; Konishi, M.; Wu, Y.; Du, H.; Sun Chung, H.; Li, L.; Boudsocq, M.; McCormack, M.; Maekawa, S.; et al. Discovery of nitrate-CPK-NLP signalling in central nutrient-growth networks. Nature 2017, 545, 311-316. [CrossRef]

81. Liu, K.-H.; Diener, A.; Lin, Z.; Liu, C.; Sheen, J. Primary nitrate responses mediated by calcium signalling and diverse protein phosphorylation. J. Exp. Bot. 2020, 71, 4428-4441. [CrossRef]

82. Sheen, J. Master regulators in plant glucose signaling networks. J. Plant Biol. 2014, 57, 67-79. [CrossRef]

83. Moore, B.; Zhou, L.; Rolland, F.; Hall, Q.; Cheng, W.-H.; Liu, Y.-X.; Hwang, I.; Jones, T.; Sheen, J. Role of the Arabidopsis Glucose Sensor HXK1 in Nutrient, Light, and Hormonal Signaling. Science 2003, 300, 332-336. [CrossRef]

84. Frommer, W.B.; Schulze, W.X.; Lalonde, S. Hexokinase, Jack-of-All-Trades. Science 2003, 300, 261-263. [CrossRef]

85. Li, L.; Liu, K.; Sheen, J. Dynamic Nutrient Signaling Networks in Plants. Annu. Rev. Cell Dev. Biol. 2021, 37, 341-367. [CrossRef] [PubMed]

86. Baena-González, E.; Rolland, F.; Thevelein, J.M.; Sheen, J. A central integrator of transcription networks in plant stress and energy signalling. Nature 2007, 448, 938-942. [CrossRef] [PubMed]

87. Zhang, Y.; Primavesi, L.F.; Jhurreea, D.; Andralojc, P.J.; Mitchell, R.A.C.; Powers, S.J.; Schluepmann, H.; Delatte, T.; Wingler, A.; Paul, M.J. Inhibition of SNF1-Related Protein Kinase1 Activity and Regulation of Metabolic Pathways by Trehalose-6-Phosphate. Plant Physiol. 2009, 149, 1860-1871. [CrossRef] [PubMed]

88. Zhai, Z.; Keereetaweep, J.; Liu, H.; Feil, R.; Lunn, J.E.; Shanklin, J. Trehalose 6-Phosphate Positively Regulates Fatty Acid Synthesis by Stabilizing WRINKLED1. Plant Cell 2018, 30, 2616-2627. [CrossRef]

89. Baena-González, E.; Lunn, J.E. SnRK1 and trehalose 6-phosphate-Two ancient pathways converge to regulate plant metabolism and growth. Curr. Opin. Plant Biol. 2020, 55, 52-59. [CrossRef]

90. Nukarinen, E.; Nägele, T.; Pedrotti, L.; Wurzinger, B.; Mair, A.; Landgraf, R.; Börnke, F.; Hanson, J.; Teige, M.; BaenaGonzalez, E.; et al. Quantitative phosphoproteomics reveals the role of the AMPK plant ortholog SnRK1 as a metabolic master regulator under energy deprivation. Sci. Rep. 2016, 6, 31697. [CrossRef]

91. Xiong, Y.; McCormack, M.; Li, L.; Hall, Q.; Xiang, C.; Sheen, J. Glucose-TOR signalling reprograms the transcriptome and activates meristems. Nature 2013, 496, 181-186. [CrossRef] [PubMed]

92. Riegler, S.; Servi, L.; Scarpin, M.R.; Godoy Herz, M.A.; Kubaczka, M.G.; Venhuizen, P.; Meyer, C.; Brunkard, J.O.; Kalyna, M.; Barta, A.; et al. Light regulates alternative splicing outcomes via the TOR kinase pathway. Cell Rep. 2021, 36, 109676. [CrossRef] [PubMed]

93. Orozco, J.M.; Krawczyk, P.A.; Scaria, S.M.; Cangelosi, A.L.; Chan, S.H.; Kunchok, T.; Lewis, C.A.; Sabatini, D.M. Dihydroxyacetone phosphate signals glucose availability to mTORC1. Nat. Metab. 2020, 2, 893-901. [CrossRef] [PubMed]

94. Brunkard, J.O.; Xu, M.; Regina Scarpin, M.; Chatterjee, S.; Shemyakina, E.A.; Goodman, H.M.; Zambryski, P. TOR dynamically regulates plant cell-cell transport. Proc. Natl. Acad. Sci. USA 2020, 117, 5049-5058. [CrossRef] [PubMed]

95. Chatterjee, S.; Xu, M.; Shemyakina, E.A.; Brunkard, J.O. Pontin/Reptin-associated complexes differentially impact plant development and viral pathology. bioRxiv 2021. [CrossRef]

96. Takeuchi, T.; Benning, C. Nitrogen-dependent coordination of cell cycle, quiescence and TAG accumulation in Chlamydomonas. Biotechnol. Biofuels 2019, 12, 292. [CrossRef] [PubMed]

97. Imamura, S.; Kawase, Y.; Kobayashi, I.; Sone, T.; Era, A.; Miyagishima, S.; Shimojima, M.; Ohta, H.; Tanaka, K. Target of rapamycin (TOR) plays a critical role in triacylglycerol accumulation in microalgae. Plant Mol. Biol. 2015, 89, 309-318. [CrossRef] [PubMed]

98. Imamura, S.; Kawase, Y.; Kobayashi, I.; Shimojima, M.; Ohta, H.; Tanaka, K. TOR (target of rapamycin) is a key regulator of triacylglycerol accumulation in microalgae. Plant Signal. Behav. 2016, 11, e1149285. [CrossRef]

99. Caldana, C.; Li, Y.; Leisse, A.; Zhang, Y.; Bartholomaeus, L.; Fernie, A.R.; Willmitzer, L.; Giavalisco, P. Systemic analysis of inducible target of rapamycin mutants reveal a general metabolic switch controlling growth in Arabidopsis thaliana. Plant J. 2013, 73, 897-909. [CrossRef]

100. Mukaida, S.; Ogawa, T.; Ohishi, K.; Tanizawa, Y.; Ohta, D.; Arita, M. The effect of rapamycin on biodiesel-producing protist Euglena gracilis. Biosci. Biotechnol. Biochem. 2016, 80, 1223-1229. [CrossRef]

101. Prioretti, L.; Avilan, L.; Carrière, F.; Montané, M.-H.; Field, B.; Grégori, G.; Menand, B.; Gontero, B. The inhibition of TOR in the model diatom Phaeodactylum tricornutum promotes a get-fat growth regime. Algal Res. 2017, 26, 265-274. [CrossRef]

102. Jüppner, J.; Mubeen, U.; Leisse, A.; Caldana, C.; Wiszniewski, A.; Steinhauser, D.; Giavalisco, P. The target of rapamycin kinase affects biomass accumulation and cell cycle progression by altering carbon/nitrogen balance in synchronized Chlamydomonas reinhardtii cells. Plant J. 2018, 93, 355-376. [CrossRef]

103. Mubeen, U.; Jüppner, J.; Alpers, J.; Hincha, D.K.; Giavalisco, P. Target of Rapamycin Inhibition in Chlamydomonas reinhardtii Triggers de Novo Amino Acid Synthesis by Enhancing Nitrogen Assimilation. Plant Cell 2018, 30, 2240-2254. [CrossRef] 
104. Upadhyaya, S.; Agrawal, S.; Gorakshakar, A.; Rao, B.J. TOR kinase activity in Chlamydomonas reinhardtii is modulated by cellular metabolic states. FEBS Lett. 2020, 594, 3122-3141. [CrossRef] [PubMed]

105. Stewart, W.M.; Dibb, D.W.; Johnston, A.E.; Smyth, T.J. The contribution of commercial fertilizer nutrients to food production. Agron. J. 2005, 97, 1-6. [CrossRef]

106. Tilman, D. The greening of the green revolution. Nature 1998, 396, 211-212. [CrossRef]

107. Veneklaas, E.J.; Lambers, H.; Bragg, J.; Finnegan, P.M.; Lovelock, C.E.; Plaxton, W.C.; Price, C.A.; Scheible, W.R.; Shane, M.W.; White, P.J.; et al. Opportunities for improving phosphorus-use efficiency in crop plants. New Phytol. 2012, 195, 306-320. [CrossRef]

108. Cordell, D.; White, S. Peak phosphorus: Clarifying the key issues of a vigorous debate about long-term phosphorus security. Sustainability 2011, 3, 2027-2049. [CrossRef]

109. Springmann, M.; Clark, M.; Mason-D'Croz, D.; Wiebe, K.; Bodirsky, B.L.; Lassaletta, L.; de Vries, W.; Vermeulen, S.J.; Herrero, M.; Carlson, K.M.; et al. Options for keeping the food system within environmental limits. Nature 2018, 562, 519-525. [CrossRef] 